\title{
MODELO COMERCIAL DE APROPIACIÓN DE LA TELESALUD PARA EMPRESAS SOCIALES DEL ESTADO - E.S.E.
}

\section{COMMERCIAL MODEL OF APPROPRIATION OF TELEHEALTH FOR SOCIAL COMPANIES OF THE STATE - E.S.E.}

\author{
Autor 1 - Magda Gioanna Cruz Suarez \\ Ms en Salud Pública y Desarrollo Social \\ Universidad Nacional Abierta y a Distancia \\ ORCID: https://orcid.org/0000-0001-6212-2968 \\ email.magda.cruz@unad.edu.co \\ Autor 2 - Paola Alvis Duffó \\ Esp. Seguridad y Salud en el Trabajo \\ Universidad Nacional Abierta y a Distancia \\ ORCID: https://orcid.org/0000-0001-6183-0137 \\ email.paola.alvis@unad.edu.co \\ Autor 3 - Myriam Leonor Torres Pérez \\ Phd. en Salud Pública \\ Universidad Nacional Abierta y a Distancia \\ ORCID: https://orcid.org/0000-0003-2923-5754 \\ email. Myriam.torres@unad.edu.co
}

\section{RESUMEN.}

Este modelo aplica para la negociación y contratación de la venta de servicios de salud con las Entidades Promotoras de Salud y demás empresas responsables de pago. Inicia con la definición y elaboración del plan operativo de contratación de servicios de salud y termina con el registro, parametrización y notificación de las nuevas tarifas y contratos en el software institucional.

Este modelo se elabora basado en ejes programáticos como el Modelo de Atención Integral en salud (MIAS) y el nuevo marco operacional Modelo de Acción Integral Territorial (MAITE), de igual forma tiene en cuenta información departamental como el documento de redes y Análisis de Situación en Salud reportados al Ministerio de Salud y Protección Social. De igual forma, el modelo fue socializado en el "Primer Encuentro de Apropiación de Telesalud en zonas de frontera" ejecutado el día 11 de junio de 2019. El modelo describe un conjunto de acciones que promueven y facilitan la atención oportuna, eficiente y eficaz, que van dirigidas a las personas, consideradas seres íntegros física y mentalmente, que además son seres sociales que pertenecen a una 
familia, que se encuentran en constante proceso de integración y adaptación a su medio ambiente físico, social y cultural.

Palabras Clave.

Modelo; Prestador de Servicios; Servicios de Salud; Telesalud

\section{ABSTRACT.}

This model applies to the negotiation and contracting of the sale of health services with Health Promotion Entities and other companies responsible for payment. It begins with the definition and preparation of the operational plan for contracting health services and ends with the registration, parameterization and notification of the new rates and contracts in the institutional software.

This model is developed based on programmatic axes such as the Comprehensive Health Care Model (MIAS) and the new operational framework Model of Comprehensive Territorial Action (MAITE), in the same way, it takes into account departmental information such as the document on networks and Situation Analysis in Health reported to the Ministry of Health and Social Protection.

Likewise, the model was socialized in the "First Telehealth Appropriation Meeting in border areas" held on June 11, 2019. The model describes a set of actions that promote and facilitate timely, efficient and effective care, they are aimed at people, considered physically and mentally whole beings, who are also social beings that belong to a family, who are in a constant process of integration and adaptation to their physical, social and cultural environment.

\section{Keywords.}

Model; Service provider; Health services; Telehealth Maximum 6 words separated ...

\section{INTRODUCCIÓN.}

El presente modelo comercial permite establecer una serie de conceptos, herramientas y procedimientos, que le permitirán a las Empresas Sociales del Estado objeto del proyecto de la UNAD - El Ministerio de Relaciones Exteriores contar con elementos que potencialicen los procesos de negociación con las Empresas Promotoras de Salud y/o Entidades 
Responsables de Pago, atendiendo los lineamientos establecidos en la normatividad que regula los servicios de Telesalud en Colombia (1).

Igualmente se espera que las Empresas Sociales del Estado desarrollen al interior de las Instituciones los procedimientos necesarios que les permita controlar los procesos de mercadeo de servicios y contractuales minimizando los riesgos.

Las Empresas Sociales del Estado enfrentan un reto de carácter estructural, porque deben solucionar un conjunto de problemáticas, entre ellas afrontar principalmente el reto gerencial y administrativo, cuyo objetivo es organizar y preparar a la organización para participar en un mercado cada vez más competitivo, al igual que prestar la mayor cantidad de servicios posibles con calidad, eficiencia y oportunidad (2).

La articulación del modelo de atención en salud con la implementación de prestación de servicios a través de la telemedicina y la Telesalud que permitirá aumentar los servicios ofertados en los portafolios de las Empresas Sociales del Estado, el desarrollo de nuevos programas y la adopción de estrategias a través del presente modelo comercial; permitirán ofrecer a las Empresas Promotoras de Salud y/o Entidades Responsables de Pago servicios con un mayor grado de competitividad y poder pactar diferentes formas de acuerdos de voluntades o formas de contratación que mejoren la productividad y facturación al interior de las Instituciones.

A través de la implementación del modelo comercial se busca identificar, analizar y dar respuesta oportuna a los posibles problemas de salud de la población objeto de atención de cada Empresa Social del Estado, asegurando dentro de un marco normativo, estrategias fundamentales en la gestión del riesgo y de prestación de servicios que pretenden organizar, incentivar y orientar a la población al uso de servicios que generen mejores estilos de vida y hábitos saludables (3).

\section{METODOLOGÍA.}

Como metodología en el proceso de realización del modelo comercial, se atendieron las siguientes etapas con las E.S.E. participantes, acorde a la complejidad de la E.S.E. y la normatividad vigente en Colombia.

- Diagnóstico y levantamiento de la información en Telesalud de la E.S.E. (4). 
- $\quad$ Caracterización de las E.S.E. en torno a complejidad y prestación de los servicios.

- $\quad$ Capacitación al personal de las E.S.E. participantes en torno al modelo.

- Socialización del modelo en audiencia pública a todos los participantes del proceso.

\section{DISCUSIÓN Y RESULTADOS.}

El modelo comercial inicia con la definición y elaboración del plan operativo de contratación de servicios de salud y termina con el registro, parametrización y notificación de las nuevas tarifas y contratos en el software institucional y define requisitos generales respecto al acuerdo de voluntades que se debe ejecutar en un proceso tales como:

1. Identificación de las partes

2. Término de duración

3. Modalidad de contratación y de pago

4. Valor total del contrato, tarifas y precios que deben ser aplicados

5. Criterios de ajuste del contrato y del valor, en caso de ser necesario

6. Nota técnica por modalidad de contratación y de pago.

7. Procedimientos e instrumentos para la autorización de los servicios de salud y su trazabilidad según la modalidad de contratación y de pago

8. Indicadores, actividades o reglas de seguimiento de acuerdo con la modalidad de contratación y de pago.

9. Proceso y operación del sistema de referencia y contra referencia

10. Periodicidad en la entrega obligatoria de datos

11. Periodicidad y forma como se adelantará el programa de auditoría

12. Procesos y procedimientos de interventoría y evaluación del cumplimiento de las obligaciones, durante la vigencia de los acuerdos de voluntades

13. Mecanismos para la solución de conflictos.

14. Procesos y términos para la liquidación o terminación de los acuerdos de voluntades.

Como resultados del modelo comercial se plantea desde la oferta de servicios de telemedicina por parte de la E.S.E. que pueden estar orientadas según las siguientes categorías entorno al nivel de complejidad, hasta la hoja de ruta que estas deben seguir para un modelo eficaz y efectivo. 


\title{
Categorías ofertadas entorno al nivel de complejidad.
}

\section{Nivel de complejidad I y II}

\author{
Oferta de servicios orientada en programas de salud.
}

- $\quad$ Promoción de la salud y detección temprana de enfermedades.

Tabla 1. Promoción de la salud y detección temprana de enfermedades

\begin{tabular}{|c|c|c|c|}
\hline PROGRAMAS P Y D & $\begin{array}{l}\text { SERVICIO (S) TELEMEDICINA } \\
\text { SUSCEPTIBLE A PRESTAR POR } \\
\text { ESE }\end{array}$ & $\begin{array}{l}\text { JUSTIFICACIÓN } \\
\text { DATOS EPIDEMIOLÓGICOS } \\
\text { DEPARTAMENTO }\end{array}$ & BENEFICIO ESPERADO \\
\hline $\begin{array}{l}\text { Planificación Familiar: } \\
\text {-Consulta planificación familiar } \\
\text { primera vez } \\
\text { - Suministro de método de } \\
\text { planificación }\end{array}$ & $\begin{array}{ll}\text { Tele } & \text { Consulta } \\
\text { Ginecobstetricia. } & \end{array}$ & $\begin{array}{l}\text { La tasa de natalidad en } \\
\text { Putumayo es notablemente } \\
\text { mayor a la del país. Se debe } \\
\text { seguir generando acciones } \\
\text { para continuar con la } \\
\text { tendencia al descenso que } \\
\text { ha surgido en Putumayo, la } \\
\text { cual se evidencia de } 33,3 \text { por } \\
\text { mil en el período } 1995-2000 \\
\text { a } 23,8 \text { por mil en el período } \\
2015-2020 \text {. }\end{array}$ & $\begin{array}{l}\text { Orientación en casos de difícil } \\
\text { elegibilidad de método por } \\
\text { condiciones clínicas del usuario o } \\
\text { morbilidades que presenten } \\
\text { contraindicaciones por } \\
\text { especialista en Ginecobstetricia. } \\
\text { Definición de manejo según } \\
\text { necesidades y preferencias, } \\
\text { contribuyendo a la disminución } \\
\text { de gestaciones no deseadas y la } \\
\text { mortalidad materna. }\end{array}$ \\
\hline $\begin{array}{l}\text { Consulta del adulto primera vez y } \\
\text { control de patologías }\end{array}$ & $\begin{array}{l}\text { Tele Consulta (Equipo } \\
\text { interdisciplinar): } \\
\text {-Medicina Interna } \\
\text { - Dermatología } \\
\text {-Otorrinolaringología } \\
\text {-Ortopedia } \\
\text {-Neurología } \\
\text {-Medicina Física y } \\
\text { rehabilitación }\end{array}$ & $\begin{array}{l}\text { El mayor número atenciones } \\
\text { prestadas según ciclo vital } \\
\text { en el departamento de } \\
\text { Putumayo en el 2014, se } \\
\text { prestó a la población en } \\
\text { adultez (27 a } 59 \text { años) en } \\
227.681 \text { atenciones } \\
\text { correspondientes a un } \\
36,3 \% \text { del total. } \\
\text { Lo anterior, relacionado con } \\
\text { las enfermedades no } \\
\text { transmisibles como primera } \\
\text { causa de morbilidad y otras } \\
\text { como musculo esqueléticas } \\
\text { y digestivas con cifras } \\
\text { relevantes que implican } \\
\text { seguimiento de patologías } \\
\text { con apoyo de especialistas. }\end{array}$ & $\begin{array}{l}\text { Apoyo por } \\
\text { especializada en dedicina } \\
\text { temprana y diagnóstico } \\
\text { oportuno de una o algunas de las } \\
\text { patologías crónicas propias de la } \\
\text { adultez, definición de manejo, } \\
\text { tratamiento y control de } \\
\text { diferentes enfermedades como: } \\
\text { cardiovasculares, del } \\
\text { metabolismo, neoplásicas, } \\
\text { musculoesqueléticas } \\
\text { osteoarticulares, neurológicas y } \\
\text { de piel. }\end{array}$ \\
\hline Consulta del joven primera vez & $\begin{array}{l}\text { Tele Consulta Pediatría/ } \\
\text { Medicina Interna }\end{array}$ & $\begin{array}{l}\text { La población entre } 10 \text { y } 29 \\
\text { años equivale al } 40 \% \text { de la } \\
\text { población actual del país y } \\
\text { representa el } 40-50 \% \text { de la } \\
\text { población económicamente } \\
\text { activa. Lo cual hace que las } \\
\text { intervenciones dirigidas a } \\
\text { este grupo sean prioritarias } \\
\text { en el contexto de la salud } \\
\text { pública. }\end{array}$ & $\begin{array}{l}\text { Apoyo por medicina } \\
\text { especializada a médico tratante } \\
\text { en detección e intervención } \\
\text { temprana de los factores de } \\
\text { riesgo o problemas de salud } \\
\text { prioritarios que se identifiquen } \\
\text { en el joven, identificando riesgos } \\
\text { relacionados con la violencia, el } \\
\text { proceso de reproducción, la } \\
\text { salud sexual y los trastornos } \\
\text { psicosociales, e interviniendo } \\
\text { con la definición de un }\end{array}$ \\
\hline
\end{tabular}




\begin{tabular}{|c|c|c|c|}
\hline & & $\begin{array}{l}\text { Los trastornos de } \\
\text { alimentación como anorexia } \\
\text { y bulimia comienzan en la } \\
\text { adolescencia, alrededor de } \\
\text { los } 17 \text { años. El consumo de } \\
\text { alcohol se inicia entre } 12 \text { y } \\
15 \text { años. La prevalencia } \\
\text { anual de alcoholismo entre } \\
12 \text { y } 29 \text { años es del } 12.2 \% \text {. La } \\
\text { prevalencia de vida de } \\
\text { consumo de tabaco entre } \\
\text { los } 12 \text { y } 29 \text { años es de } \\
26.35 \%\end{array}$ & $\begin{array}{l}\text { diagnóstico oportuno y } \\
\text { tratamiento farmacológico de } \\
\text { alteraciones o enfermedades. }\end{array}$ \\
\hline $\begin{array}{l}\text { Consulta crecimiento } \\
\text { desarrollo primera vez }\end{array}$ & $\begin{array}{l}\text { Tele Consulta: } \\
\text { - Pediatría } \\
\text {-Nutrición y Dietética }\end{array}$ & $\begin{array}{l}\text { La Enfermedad Diarreica } \\
\text { Aguda y la Desnutrición son } \\
\text { causas muy importantes de } \\
\text { mortalidad de los menores } \\
\text { de } 5 \text { años del Putumayo, con } \\
\text { tasas de mortalidad } \\
\text { elevadas y superiores a las } \\
\text { del nivel nacional. } \\
\text { En los menores de } 5 \text { años, la } \\
\text { mortalidad ocasionada por } \\
\text { las afecciones originadas en } \\
\text { el período perinatal, las } \\
\text { malformaciones congénitas, } \\
\text { deformidades y anomalías } \\
\text { cromosómicas, las } \\
\text { enfermedades infecciosas y } \\
\text { parasitarias y las } \\
\text { enfermedades del sistema } \\
\text { respiratorio. }\end{array}$ & $\begin{array}{l}\text { Valoración integral del menor } \\
\text { por equipo interdisciplinario } \\
\text { según manual de AIEPI, } \\
\text { evaluación de alteraciones del } \\
\text { desarrollo cognoscitivo y motriz } \\
\text { e instauración de manejo. } \\
\text { Valoración Recién Nacido con } \\
\text { malformaciones } \\
\text { Diagnóstico nutricional del } \\
\text { menor y establecimiento del } \\
\text { plan dietario ante alteraciones. }\end{array}$ \\
\hline $\begin{array}{l}\text { Detección cáncer y apoyo en } \\
\text { manejo } \\
\text {-Cáncer Cuello Uterino y } \\
\text { realización de citología } \\
\text { - Cáncer Seno y realización de } \\
\text { mamografía } \\
\text { - Cáncer de próstata } \\
\text { - Cáncer Estómago }\end{array}$ & 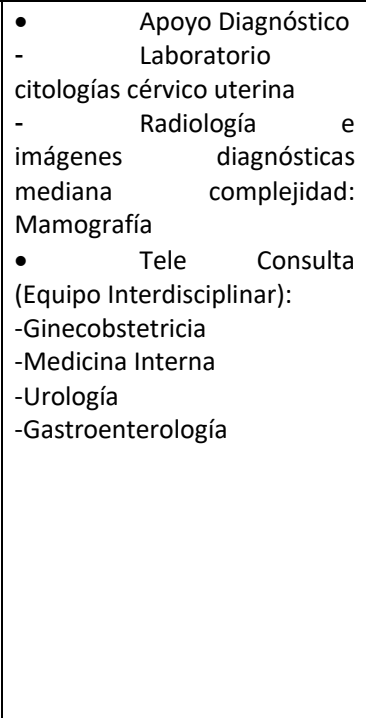 & $\begin{array}{l}\text { La tasa de mortalidad por } \\
\text { neoplasias se incrementó en } \\
\text { el período 2006-2009, } \\
\text { descendiendo en el período } \\
\text { 2010-2012, para aumentar } \\
\text { nuevamente en 2013. } \\
\text { Las neoplasias, en especial el } \\
\text { tumor maligno de estómago } \\
\text { y órganos digestivos, el } \\
\text { tumor maligno de próstata } \\
\text { en los hombres y en las } \\
\text { mujeres el tumor maligno de } \\
\text { cuello de útero y mama. } \\
\text { El indicador de Mortalidad } \\
\text { general por grandes causas } \\
\text { en el territorio reporta una } \\
\text { tasa de mortalidad por } \\
\text { Neoplasias en población } \\
\text { mujeres de 69,34. }\end{array}$ & $\begin{array}{l}\text { Apoyo en la detección oportuna } \\
\text { de lesiones preneoplásicas y } \\
\text { neoplásicas del cuello uterino, } \\
\text { mediante la solicitud de apoyos } \\
\text { diagnósticos de baja, mediana } \\
\text { complejidad y alta e } \\
\text { interpretación por especialistas, } \\
\text { como citología cérvico uterina, } \\
\text { colposcopia y biopsia. } \\
\text { Diagnóstico especializado y } \\
\text { oportuno de cáncer y definición } \\
\text { de tratamiento. }\end{array}$ \\
\hline $\begin{array}{l}\text { Control Prenatal para Gestantes: } \\
\text {-Tamizaje para sífilis } \\
\text { - Tamizaje para VIH (incluye } \\
\text { asesoría pre) } \\
\text { - Tamizaje para hepatitis b } \\
\text { - Asesoría en lactancia materna }\end{array}$ & $\begin{array}{l}\text { - Tele Consulta } \\
\text { (Equipo interdisciplinarios): } \\
\text {-Ginecobstetricia } \\
\text {-Endocrinología } \\
\text {-Nutrición y Dietética } \\
\text { - Toma de muestras } \\
\text { de laboratorio clínico, baja, } \\
\text { mediana y alta complejidad. }\end{array}$ & $\begin{array}{l}\text { La razón de mortalidad } \\
\text { materna, a pesar de mostrar } \\
\text { tendencia a la disminución, } \\
\text { es superior en todos los } \\
\text { años a la del nivel nacional, } \\
\text { por lo que se presenta como } \\
\text { una prioridad en el } \\
\text { departamento. }\end{array}$ & $\begin{array}{l}\text { Valoración del riesgo obstétrico } \\
\text { y seguimiento de control } \\
\text { prenatal, detectando } \\
\text { tempranamente por } \\
\text { especialistas alteraciones. } \\
\text { Diagnóstico, Tratamiento y } \\
\text { Control de la patología tiroidea }\end{array}$ \\
\hline
\end{tabular}




\begin{tabular}{|c|c|c|c|}
\hline & & & $\begin{array}{l}\text { en el embarazo: Hipotiroidismo e } \\
\text { hipertiroidismo. } \\
\text { Diagnóstico, tratamiento y } \\
\text { control de Bajo peso u Obesidad } \\
\text { en proceso de gestación. } \\
\text { Estructura y supervisión de plan } \\
\text { dietario de la gestante. }\end{array}$ \\
\hline $\begin{array}{ll}- & \text { Enfermedades } \\
\text { Crónicas No transmisibles: } \\
\text { - } & \text { Hipertensión } \\
\text { - } & \text { Diabetes } \\
\text { - } & \text { Enfermedad } \\
\text { Pulmonar Obstructiva. }\end{array}$ & $\begin{array}{l}\text { - Apoyos } \\
\text { diagnósticos y/o Terapéutico } \\
\text {-Diagnóstico Cardiovascular: } \\
\text { Electrocardiograma, } \\
\text { ecocardiograma, prueba de } \\
\text { esfuerzo, test de holter } \\
\text { arterial, test de holter } 24 \\
\text { horas. } \\
\text {-Función } \\
\text { Espirometría. Pulmonar: } \\
\text { - Radiología e imágenes } \\
\text { diagnósticas: Radiología } \\
\text { convencional, ultrasonido, } \\
\text { resonancia magnética y } \\
\text { tomografía computarizada. } \\
\text { - Tele consulta } \\
\text { (Equipo Interdisciplinar): } \\
\text {-Medicina Interna } \\
\text { - Nutrición Y Dietética } \\
\text {-Cardiología } \\
\text {-Endocrinología } \\
\text {-Nefrología } \\
\text {-Neumología } \\
\text {-Oftalmología }\end{array}$ & $\begin{array}{l}\text { La Primera gran causa de } \\
\text { morbilidad en el } \\
\text { departamento de Putumayo } \\
\text { son las enfermedades no } \\
\text { transmisibles }(46.74 \%) \text {. } \\
\text { La prevalencia por } \\
\text { hipertensión arterial en para } \\
\text { el año } 2014 \text { es de } 2.14 \text { por } \\
\text { cada } 100.000 \text { habitantes. }\end{array}$ & $\begin{array}{l}\text { Valoración integral de } \\
\text { enfermedad crónica } \\
\text { hipertensión arterial y diabetes } \\
\text { mellitus, control de patología, } \\
\text { ajuste de dosis de farmacológica. } \\
\text { Valoración de la capacidad } \\
\text { pulmonar, y funcional del } \\
\text { paciente con enfermedad } \\
\text { pulmonar obstructiva crónica, } \\
\text { con médicos especialistas y } \\
\text { manejo integral de patología. } \\
\text { Control por nutrición en } \\
\text { pacientes con patologías } \\
\text { crónicas y establecimiento de } \\
\text { plan dietario como parte del } \\
\text { tratamiento y control de otros } \\
\text { factores de riesgos asociados a la } \\
\text { enfermedad. }\end{array}$ \\
\hline
\end{tabular}

Fuente: Elaboración Propia.

\section{- $\quad$ Programas de alto costo.}

Tabla 2. Programas de alto costo

\begin{tabular}{|c|c|c|c|}
\hline $\begin{array}{l}\text { PROGRAMAS } \\
\text { ATENCIÓN GRUPOS DE RIESGO }\end{array}$ & $\begin{array}{l}\text { SERVICIO (S) TELEMEDICINA } \\
\text { SUSCEPTIBLE A PRESTAR POR } \\
\text { ESE }\end{array}$ & $\begin{array}{l}\text { JUSTIFICACIÓN } \\
\text { DATOS EPIDEMIOLÓGICOS } \\
\text { DEPARTAMENTO }\end{array}$ & BENEFICIO ESPERADO \\
\hline $\begin{array}{l}\text { Programas Alto Costo: } \\
\text { Enfermedad Renal Crónica. }\end{array}$ & $\begin{array}{l}\text { Apoyos } \\
\text { diagnósticos y/o Terapéutico } \\
\text {-Diagnóstico Cardiovascular: } \\
\text { Electrocardiograma, } \\
\text { ecocardiograma, prueba de } \\
\text { esfuerzo, test de holter } \\
\text { arterial, test de holter } 24 \\
\text { horas. } \\
\text {-Función Pulmonar: } \\
\text { Espirometría. } \\
\text { - Radiología e imágenes } \\
\text { diagnósticas: Radiología } \\
\text { convencional, ultrasonido, } \\
\text { resonancia magnética y } \\
\text { tomografía computarizada. } \\
\text { Tele consulta } \\
\text { (Equipo Interdisciplinar): } \\
\text {-Medicina Interna } \\
\text { - Nutrición Y Dietética } \\
\text {-Cardiología }\end{array}$ & $\begin{array}{l}\text { La morbilidad por eventos } \\
\text { de alto costo es una } \\
\text { prioridad en el } \\
\text { departamento } \\
\text { Putumayo, En } 2014 \text { se } \\
\text { reportaron } 946 \text { personas } \\
\text { con enfermedad renal } \\
\text { crónica; en el estadio } 2 \text { se } \\
\text { encuentra el mayor número } \\
\text { de casos (396 personas), } \\
\text { quienes representan el } 42 \% \text {, } \\
\text { seguido de las personas en } \\
\text { estadio } 3 \text { con el } 35 \% \text {. }\end{array}$ & $\begin{array}{l}\text { Valoración integral de } \\
\text { enfermedad renal crónica, } \\
\text { control según estadio de } \\
\text { patología por equipo } \\
\text { interdisciplinario y manejo de } \\
\text { comorbilidades, orientación en } \\
\text { tratamiento farmacológico y } \\
\text { rehabilitación. }\end{array}$ \\
\hline
\end{tabular}




\begin{tabular}{|c|c|c|c|}
\hline & $\begin{array}{l}\text {-Endocrinología } \\
\text {-Nefrología } \\
\text { - } \quad \text {-Neumología }\end{array}$ & & \\
\hline Programas Alto Costo: VIH & 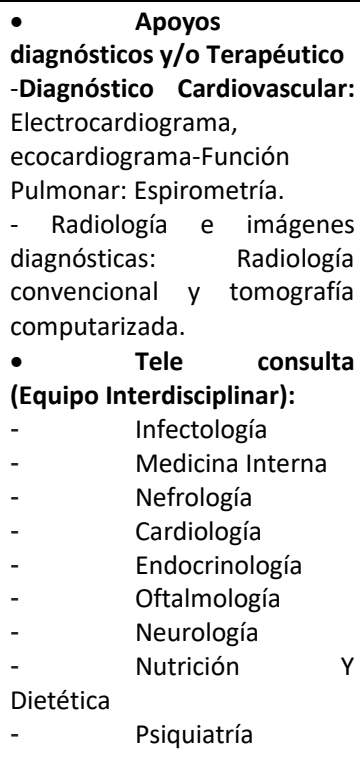 & $\begin{array}{l}\text { La tasa de VIH en el } \\
\text { departamento de Putumayo } \\
\text { es } 18,6 \times 100.000 \text { habitantes, } \\
\text { cifra que exige especial } \\
\text { intervención en el control de } \\
\text { usuarios con patología. }\end{array}$ & $\begin{array}{l}\text { Apoyo en manejo integral de } \\
\text { patología VIH por equipo } \\
\text { interdisciplinario de especialistas } \\
\text { y comorbilidades, orientación a } \\
\text { médico tratante en tratamiento } \\
\text { con antirretrovirales, reducción } \\
\text { de complicaciones y } \\
\text { hospitalizaciones y contención } \\
\text { de los costos del tratamiento y la } \\
\text { mortalidad por la enfermedad. } \\
\text { Realización de Teleeducación a } \\
\text { paciente y personal de salud } \\
\text { enfocado en la prevención de } \\
\text { transmisión de VIH. }\end{array}$ \\
\hline $\begin{array}{l}\text { Programas } \\
\text { Enfermedades } \\
\text { Cardiovascular: } \\
\text { - } \quad \text { Riesgo } \\
\text { Coronaria } \\
\text { - } \quad \text { Insuficiencia Cardiaca } \\
\text { - Obesidad }\end{array}$ & $\begin{array}{l}\text { - Apoyos } \\
\text { diagnósticos y/o Terapéutico } \\
\text {-Diagnóstico Cardiovascular: } \\
\text { Electrocardiograma, } \\
\text { ecocardiograma, prueba de } \\
\text { esfuerzo, test de holter } \\
\text { arterial, test de holter } 24 \\
\text { horas. } \\
\text {-Función } \\
\text { Espirometría. Pulmonar: } \\
\text { - Radiología e imágenes } \\
\text { diagnósticas: Radiología } \\
\text { convencional, ultrasonido. } \\
\text { - Tele consulta } \\
\text { (Equipo Interdisciplinar): } \\
\text {-Medicina Interna } \\
\text { - Nutrición Y Dietética } \\
\text {-Cardiología } \\
\text {-Endocrinología }\end{array}$ & $\begin{array}{l}\text { Las enfermedades } \\
\text { cardiovasculares en las } \\
\text { encuentran en las } \\
\text { prioridades en salud pública } \\
\text { del departamento, debido a } \\
\text { que están en las primeras } \\
\text { causas de morbilidad en el } \\
\text { departamento. }\end{array}$ & $\begin{array}{l}\text { Valoración integral del riesgo } \\
\text { cardiovascular, usando apoyos } \\
\text { diagnósticos oportunos que } \\
\text { permiten estadificar el estadio } \\
\text { hipertensivo, ajustar } \\
\text { tratamiento farmacológico e } \\
\text { identificar otros factores de } \\
\text { riesgos y prevenir asociados } \\
\text { como falla cardiaca o infarto } \\
\text { agudo de miocardio. }\end{array}$ \\
\hline
\end{tabular}

Fuente: Elaboración Propia

\section{- $\quad$ Oferta por servicios.}

Tabla 3. Oferta de servicios

\begin{tabular}{|c|c|c|}
\hline SERVICIOS DE TELEMEDICINA & $\begin{array}{l}\text { JUSTIFICACIÓN } \\
\text { DATOS } \quad \text { EPIDEMIOLÓGICOS } \\
\text { DEPARTAMENTO }\end{array}$ & BENEFICIO ESPERADO \\
\hline $\begin{array}{l}\text { Apoyo diagnóstico y/o Terapéutico } \\
\text {-Diagnóstico Cardiovascular: Electrocardiograma. }\end{array}$ & \multirow{3}{*}{$\begin{array}{l}\text { Las enfermedades } \\
\text { cardiovasculares se encuentran } \\
\text { en las prioridades en salud pública } \\
\text { del departamento, debido a que } \\
\text { están en las primeras causas de } \\
\text { morbilidad en el departamento. }\end{array}$} & \multirow{3}{*}{$\begin{array}{l}\text { Apoyo diagnóstico en Valoración } \\
\text { integral del riesgo cardiovascular, que } \\
\text { permiten estadificar el estadio } \\
\text { hipertensivo, ajustar tratamiento } \\
\text { farmacológico, conocer estado de } \\
\text { funcionalidad cardiaca y otros } \\
\text { factores de riesgo, con el objetivo de } \\
\text { identificar eventos como falla cardiaca } \\
\text { o infarto agudo de miocardio. }\end{array}$} \\
\hline $\begin{array}{l}\text { Apoyo diagnóstico y/o Terapéutico } \\
\text {-Diagnóstico Cardiovascular: Test de holter arterial } \\
\text { o Monitoreo Ambulatorio de Presión Arterial } \\
\text { (MAPA). }\end{array}$ & & \\
\hline Apoyo diagnóstico y/o Terapéutico & & \\
\hline
\end{tabular}




\begin{tabular}{|c|c|c|}
\hline $\begin{array}{l}\text {-Diagnóstico Cardiovascular: Test de holter de ritmo } \\
24 \text { horas. }\end{array}$ & & \\
\hline $\begin{array}{l}\text { Apoyo diagnóstico y/o Terapéutico } \\
\text {-Diagnóstico Cardiovascular: Ecocardiograma }\end{array}$ & & \\
\hline $\begin{array}{l}\text { Apoyos diagnósticos y/o Terapéutico } \\
\text { - Diagnóstico Cardiovascular: Prueba de esfuerzo }\end{array}$ & & \\
\hline $\begin{array}{l}\text { Apoyos diagnósticos y/o Terapéutico } \\
\text {-Función Pulmonar: Espirometría }\end{array}$ & $\begin{array}{l}\text { La Primera gran causa de } \\
\text { morbilidad en el departamento } \\
\text { de Putumayo son las } \\
\text { enfermedades no transmisibles } \\
(46.74 \%) \text {. }\end{array}$ & $\begin{array}{l}\text { Apoyo diagnóstico en la Valoración de } \\
\text { la capacidad pulmonar, y funcional del } \\
\text { paciente con enfermedad pulmonar } \\
\text { obstructiva crónica, a médico tratante } \\
\text { y médicos para definición de } \\
\text { diagnóstico y manejo integral de } \\
\text { patología. }\end{array}$ \\
\hline $\begin{array}{l}\text { Apoyos diagnósticos y/o Terapéutico } \\
\text { - Radiología e imágenes diagnósticas: Radiología } \\
\text { convencional, tomografía axial computarizada, } \\
\text { resonancia magnética, mamografía. }\end{array}$ & $\begin{array}{l}\text { En el departamento de Putumayo } \\
\text { para el 2014, se reportaron } \\
627.031 \text { atenciones, de las cuales } \\
\text { el } 41 \% \text { se prestaron a los hombres } \\
(257.620) \text { y el } 59 \% \text { a las mujeres } \\
(369.411) \text { en los diferentes } \\
\text { servicios de las ESE. }\end{array}$ & $\begin{array}{l}\text { Apoyo diagnóstico en la Valoración de } \\
\text { diferentes patologías mediante } \\
\text { imágenes diagnósticas que permiten } \\
\text { identificar alteraciones en estructuras } \\
\text { anatómicas y funcionales para } \\
\text { definición de diagnósticos por médico } \\
\text { tratante o especialista. }\end{array}$ \\
\hline $\begin{array}{l}\text { Tele consulta } \\
\text { Especialidades: } \\
\text { Medicina Interna } \\
\text { Neurología } \\
\text { Psiquiatría } \\
\text { Pediatría } \\
\text { Dermatología } \\
\text { Otorrinolaringología } \\
\text { Ortopedia } \\
\text { Neurología } \\
\text { Medicina Física y rehabilitación } \\
\text { Ginecobstetricia } \\
\\
\text { Subespecialidades: } \\
\text { Nefrología } \\
\text { Cardiología } \\
\text { Endocrinología } \\
\text { Oftalmología } \\
\text { Infectología } \\
\text { Neumología } \\
\text { Otras: } \\
\text { Nutrición Y Dietética }\end{array}$ & & $\begin{array}{l}\text { Apoyo por medicina especializada a } \\
\text { médico tratante mediante } \\
\text { interconsulta en donde le orienta en la } \\
\text { detección oportuna de alteraciones en } \\
\text { salud, definición de diagnósticos, } \\
\text { tratamiento y control de patologías } \\
\text { para intervención temprana de los } \\
\text { factores de riesgo o problemas de } \\
\text { salud prioritarios que se identifiquen } \\
\text { en los usuarios. }\end{array}$ \\
\hline
\end{tabular}

Fuente: Elaboración Propia

\section{Nivel de complejidad III}

Para el nivel III se presentan las ofertas de servicios de los niveles I y II más la oferta de unidad de cuidados intensivos así:

Oferta de servicios orientada en programas de salud.

- $\quad$ Promoción de la salud y detección temprana de enfermedades.

- Programas de alto costo.

- Oferta por servicios 
- $\quad$ Oferta unidad de cuidados intensivos.

Tabla 4. Oferta unidad de cuidados intensivos

\begin{tabular}{|c|c|c|c|c|}
\hline ATENCIÓN & DESCRIPCIÓN & $\begin{array}{c}\text { SERVICIO (S) } \\
\text { TELEMEDICINA } \\
\text { SUSCEPTIBLE A PRESTAR } \\
\text { POR ESE }\end{array}$ & $\begin{array}{l}\text { JUSTIFICACIÓN } \\
\text { DATOS EPIDEMIOLÓGICOS } \\
\text { DEPARTAMENTO }\end{array}$ & BENEFICIO ESPERADO \\
\hline $\begin{array}{lr}- & \text { Enfermed } \\
\text { ades } & \text { como } \\
\text { Insuficiencia cardiaca } \\
\text { y } \quad \text { EPOC } & \text { con } \\
\text { comorbilidades } & 0 \\
\text { complicaciones } & \text { de } \\
\text { riesgo: } & \text { IAM, } \\
\text { tromboembolismo }\end{array}$ & $\begin{array}{l}\text { Servicios de Atención } \\
\text { en condiciones de } \\
\text { salud crítica } \\
\text { (Terapias intensivas, } \\
\text { unidades coronarias, } \\
\text { unidades pediátricas, } \\
\text { unidades neonatales, } \\
\text { unidades de } \\
\text { quemado entre } \\
\text { otras) en Unidad de } \\
\text { Cuidados intensivos } \\
\text { en zonas donde } \\
\text { carecen de Médicos } \\
\text { Especialistas }\end{array}$ & $\begin{array}{l}\text { - Apoyos } \\
\text { diagnósticos y/o } \\
\text { Terapéutico } \\
\text {-Diagnóstico } \\
\text { Cardiovascular: } \\
\text { Electrocardiograma, } \\
\text { ecocardiograma, prueba de } \\
\text { esfuerzo, test de holter } \\
\text { arterial, test de holter } 24 \\
\text { horas. } \\
\text {-Función Pulmonar: } \\
\text { Espirometría. } \\
\text { - Radiología e imágenes } \\
\text { diagnósticas: Radiología } \\
\text { convencional, ultrasonido, } \\
\text { resonancia magnética y } \\
\text { tomografía computarizada. } \\
\text { - Tele consulta } \\
\text { (Equipo Interdisciplinar): } \\
\text {-Medicina Interna } \\
\text { - Nutrición Y Dietética } \\
\text {-Cardiología } \\
\text {-Endocrinología } \\
\text {-Nefrología } \\
\text {-Neumología } \\
\text {-Oftalmología } \\
\text { - Tele UCl }\end{array}$ & $\begin{array}{l}\text { Las enfermedades } \\
\text { cardiovasculares y crónicas } \\
\text { se encuentran en las } \\
\text { prioridades en salud } \\
\text { pública del departamento, } \\
\text { debido a que están en las } \\
\text { primeras causas de } \\
\text { morbilidad en el } \\
\text { departamento. }\end{array}$ & 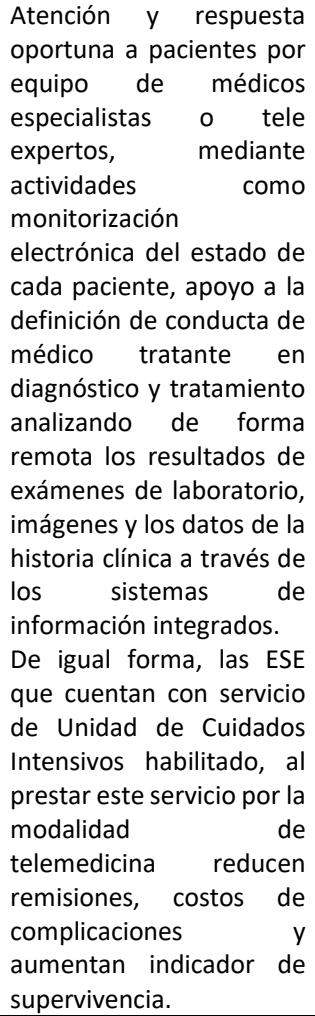 \\
\hline
\end{tabular}

Fuente: Elaboración Propia

Finalmente, para generar una dinámica lúdica en la aplicación del modelo y en aras de un aprendizaje del mismo, el modelo generó una hoja de ruta para la implementación a través de estrategias comerciales (Tabla $5)$.

Tabla 5. Hoja de ruta modelo comercial y oferta de servicios de telemedicina E.S.E. HOJA DE RUTA MODELO COMERCIAL Y OFERTA DE SERVICIOS DE TELEMEDICINA E.S.E.

\begin{tabular}{|l|l|l|l|}
\hline $\mathbf{N}^{\circ}$ & \multicolumn{1}{|c|}{ PROCESO } & CUMPLE & NO CUMPLE \\
\hline 1 & $\begin{array}{l}\text { Identificación de las Entidades Responsables de Pago con las cuales se negociará y } \\
\text { consolidación del plan operativo de contratación y el cronograma de negociación de } \\
\text { tarifas. }\end{array}$ & $\begin{array}{l}\text { Evaluación de tarifas contratadas con centro de referencia de telemedicina según } \\
\text { servicio. }\end{array}$ & $\begin{array}{l}\text { Evaluación de la red de servicios disponible para la atención de los afiliados por parte } \\
\text { Pe los aseguradores (Estructura y capacidad instalada de la red de Instituciones } \\
\text { suplir. }\end{array}$ \\
\hline $\mathbf{3}$ & $\begin{array}{l}\text { Evaluación de la Caracterización, perfil uso de servicios y perfil epidemiológico de las } \\
\text { EAPB del departamento para identificar necesidades a suplir. }\end{array}$ & & \\
\hline
\end{tabular}




\begin{tabular}{|l|l|l|l|}
5 & $\begin{array}{l}\text { Revisión de los manuales tarifarios y unidad de pago por capitación definida según } \\
\text { normatividad vigente. } \\
\text { Nota: Las E.S.E de municipios de frontera cuentan con prima adicional, lo cual les da } \\
\text { un margen más amplio de negociación en materia de precios de los servicios ofertados. } \\
\text { (Anexo 1, Resolución } 5858 \text { del } 26 \text { de diciembre de 2018) }\end{array}$ & \\
\hline 6 & $\begin{array}{l}\text { Estructuración, definición de procedimientos, servicios y productos que la ESE ofertará } \\
\text { a las entidades responsables de pago (EAPB), costeo de las ofertas comerciales, } \\
\text { creación y parametrización de los mismos en el software institucional. }\end{array}$ & \\
\hline 7 & $\begin{array}{l}\text { Elaboración, estructuración de las minutas, anexos u otrosíes y legalización de los } \\
\text { mismos mediante la suscripción por los representantes legales de las partes y el envío } \\
\text { de la copia a la Entidad con la que se contrata. }\end{array}$ & & \\
\hline 8 & $\begin{array}{l}\text { Negociación de las tarifas, sus incrementos anuales y gestión, solicitud y envío de toda } \\
\text { la documentación requerida por las partes para legalizar la relación contractual. }\end{array}$ & & \\
\hline 9 & $\begin{array}{l}\text { Creación, parametrización de todo lo convenido con las EAPB, notificación y } \\
\text { socialización a las áreas de la E.S.E involucradas (operativas y administrativas). }\end{array}$ & \\
\hline 10 & $\begin{array}{l}\text { Inicio de prestación de servicios bajo la modalidad de Telemedicina y seguimiento hoja } \\
\text { de ruta “Apropiación Modelo de atención Telesalud en E.S.E” }\end{array}$ & \\
\hline
\end{tabular}

Fuente: Elaboración Propia

\section{CONCLUSIONES.}

El diseño del Comercial para las Empresas Sociales del Estado- E.S.E seleccionadas se realiza y se entregan 33 documentos, uno por cada institución.

El modelo se socializa en el "Primer Encuentro de Apropiación de Telesalud en zonas de frontera" ejecutado el día 11 de junio a las personas involucradas en el proceso y a todas las ESE, como parte de la dinámica de este.

Este modelo se elabora basado en normatividad vigente de contratación entre instituciones prestadoras de servicios de salud y aseguradores, de igual forma, tiene en cuenta las diferentes modalidades de contratación y manuales tarifarios empleados en el sector salud para la oferta y negociación de servicios.

El modelo comercial establece conceptos, herramientas y procedimientos, que le permiten a las Empresas Sociales del Estado, contar con elementos que potencialicen los procesos de negociación con las Empresas Promotoras de Salud y/o Entidades Responsables de Pago y desarrollar al interior de las Instituciones los procedimientos necesarios para control de los procesos de mercadeo de servicios y contractuales minimizando los riesgos.

\section{BIBLIOGRAFÍA.}


1. Congreso de la República de Colombia. Ley 1419 de 2010. Por la cual se establecen los lineamientos para el desarrollo de la telesalud en Colombia. 2010. Consultado marzo 2019. http://wsp.presidencia.gov.co/Normativa/Leyes/Documents/ley1419131 22010.pdf

2. Ministerio de la Protección Social. Decreto 0133 de 2010. Por el cual se adoptan medidas tendientes a garantizar el acceso, oportunidad, continuidad, calidad y eficiencia en la prestación de los servicios de salud, y se dictan otras disposiciones. 2010. Consultado marzo 2019. https://www.minsalud.gov.co/sites/rid/Lists/BibliotecaDigital/RIDE/DE/D IJ/decreto-0133-de-2010.pdf

3. Congreso de la República de Colombia. Ley 1122 de 2007 Por la cual se hacen algunas modificaciones en el Sistema General de Seguridad Social en Salud

y se dictan otras disposiciones. 2007. Consultado marzo 2019. https://www.minsalud.gov.co/sites/rid/Lists/BibliotecaDigital/RIDE/DE/D IJ/ley-1122-de-2007.pdf

4. Ministerio de Relaciones Exteriores. Universidad Nacional Abierta y a Distancia. Documento Diagnóstico Inicial de 11 E.S.E. en la Apropiación de la Telesalud en el Modelo Integral de Atención en Salud de treinta y cuatro (34) Empresas Sociales del Estado. 2018. 